\title{
The cost of catastrophe: Why putting a price-tag on disaster is our best protection
}

Written by: Catherine Gamper, OECD Public Governance Directorate

Last update: 29 January 2020

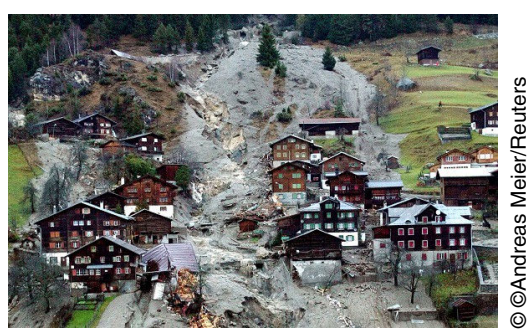

The cost of catastrophe: Why putting a price-tag on disaster is our best protection

In June 2015, a small village in the Austrian Alps was buried under a massive landslide after days of intense rain. Thanks to accurate weather forecasts and early warning systems, no one was hurt in the landslide but it caused considerable damage to the local economy and people's livelihoods.

OECD countries have gotten much better at preparing for and responding to disasters, and fatality rates have gone down. What we're not so good at, however, is reducing the economic fallout from natural disasters. Because of budgetary constraints, countries give investment in risk prevention less priority, and the cost of disaster is mounting.

Minimising disaster-related costs requires knowledge about the type of hazards that are common in a certain area, the likelihood they will occur, and the intensity their occurrence is expected to be. OECD countries have the technical capacity to understand well-established hazards. Results of such hazard analyses are widely available online thanks to high-resolution mapping tools.

Even with a better understanding of a region's recurring hazards, though, decision-makers lack a systematic understanding of risks; that is, the extent to

1 www.oecdobserver.org I The cost of catastrophe: Why putting a price-tag on disaster is our best protection 
which identified hazards threaten and expose populations and assets such as homes, and transport and communications infrastructure to potential damage. Risk assessment includes the estimated costs that can ensue from a wellestablished hazard and the geographical and economic radius of damage.

When governments have poor visibility on how much damage a hazard might cause, it is hard for them to make effective policy decisions. Good-quality information about prevailing risks helps local governments make better decisions about land use: they may decide to convert built areas into grasslands that function as flood expansion zones, for instance. It also helps governments make effective investments in physical prevention measures.

When applied however, risk information can be extremely tricky business. Physical risk reduction investments can have a surprisingly opposite effect to what's intended. In the case of the alpine landslide disaster, extensive investments made to protect the village, such as retention walls, may have contributed to a "false" sense of security, encouraging more house construction, for example, and the expansion of local public infrastructure. In the end, this increased rather than decreased damage.

After the landslide, the mayor of the alpine village told a local newspaper, "The good news is that the families who lost their homes won't be moving away. They're staying right here." While this can indeed be taken as happy news, it does present a political-economic conundrum. Mayors, who are often in charge of local land use and construction permit decisions, and who depend on local property tax income, have an interest in going back to the way things were before disaster hit. And as risk prevention is co-financed by other levels of government, there is less consideration of the real costs of rebuilding homes and businesses exactly as they were in disaster areas. It is entirely understandable that people want to stay in places they have grown attached to even if there is the constant threat of flood or volcanic eruption. But can we justify that economically?

@OECD Observer April 2018

\section{References}

OECD (2018), National Risk Assessments: A Cross Country Perspective, OECD Publishing, Paris, http://dx.doi.org/http://dx.doi.org/10.1787/9789264287532-en

http://www.oecd.org/gov/assessing-the-real-cost-of-disasters-9789264298798en.htm http://www.oecd.org/gov/assessing-the-real-cost-ofdisasters-9789264298798-en.htm

OECD (2017), Boosting Disaster Prevention through Innovative Risk Governance: Insights from Austria, France and Switzerland, OECD Reviews of Risk Management Policies, OECD Publishing, Paris, http://dx.doi.org/http:// dx.doi.org/10.1787/9789264281370-en

2 www.oecdobserver.org I The cost of catastrophe: Why putting a price-tag on disaster is our best protection 
OECD (2015), The Changing Face of Strategic Crisis Management, OECD Reviews of Risk Management Policies, OECD Publishing, Paris, http://dx.doi.org/http:// dx.doi.org/10.1787/9789264249127-en

OECD (2015), Disaster Risk Financing: A global survey of practices and challenges http://dx.doi.org/http://dx.doi.org/10.1787/9789264234246-en

OECD (2014), Boosting Resilience through Innovative Risk Governance, OECD Reviews of Risk Management Policies, OECD Publishing, Paris http://dx.doi.org/ http://dx.doi.org/10.1787/9789264209114-en

http://www.oecd.org/finance/disaster-risk-financing.htm http://www.oecd.org/ finance/disaster-risk-financing.htm 